\title{
Botulinum toxin; indications, success rates and complications in the management of horizontal strabismus in Saudi Arabia.
}

\author{
Abdulaziz A Al Taisan ${ }^{*}$, Fatemah T Al Shamlan², Abdulmohsen K Al Mulhim ${ }^{3}$, Abdulaziz I \\ Alsomali $^{1}$, Adi M Al Owaifeer ${ }^{1}$ \\ ${ }^{1}$ Ophthalmology Department, King Faisal University, Prince Faisal bin Fahd st, 31982, Hofuf, Saudi Arabia \\ ${ }^{2}$ Dhahran Eye Specialist Hospital, Al Jamiah, Dhahran 34257 7630, Saudi Arabia \\ ${ }^{3}$ Ophthalmology Department, Al Jouf University, Sakaka 72388, Saudi Arabia
}

\begin{abstract}
Introduction: This study aims to analyze the indications, effectiveness and side effects of Botulinum toxin in the management of different horizontal strabismus entities.

Methods: A retrospective analysis of cases underwent botulinum toxin injection for strabismus in Dhahran Eye Hospital from November 2013 till September 2016 where no previous surgery or intervention have been performed or a previous facial or ocular trauma. Main success indicator was a remaining angle of less than 10 prism diopter.

Results: A total of 74 cases were included. $52.7 \%$ males and $47.3 \%$ females. Age ranged from two months to forty-five years. The most prevalent diagnosis was partially accommodative esotropia (PAET). The mean angle of deviation was 37.3 prism diopters (PD) with a range of 10 to $90 \mathrm{PD}$. Overall success rate was $54 \%$ with PAET scoring the highest $(\mathbf{7 0 . 6 \% )}$. No clinical significance was found regarding age, angle of deviation or the presence of amblyopia. However, the absence of inferior oblique overaction was statistically significant on the success rate of infantile esotropia. No serious peri-operative complications were documented.

Conclusion: Botulinum toxin represents a cost effective, safe, repeatable alternative to surgery in the management of different entities of horizontal strabismus. Success rate differs in different diagnoses with PAET scoring the highest. Presence of inferior oblique overaction leads to a significant lower rate of success.
\end{abstract}

Keywords: Botulinum toxin, Botox, Strabismus, Esotropia, Exotropia.

Accepted on January 24, 2018

\section{Introduction}

Botulinum toxin is a neurotoxin produced by an anaerobic gram-positive rod; Clostridium botulinum which is found in water, soil and gastrointestinal tracts of animals [1]. $C$. botulinum produces eight exotoxins (A, B, C1, C2, D, E, F, G) each is antigenically distinguishable. The most potent exotoxin is type A, followed by type B and F. Types A, B and E are commonly associated with botulism in humans [2].

Botulinum toxin is composed of a heavy $(\mathrm{H})$ chain and a light (L) chain. The $\mathrm{H}$ chain binds the toxin to the surface of presynaptic motor nerve endings. After which, the toxin is endocytosed. The paralyzing effect is produced by the $\mathrm{L}$ chain where it interacts with different proteins (synaptosomal associated protein (SNAP) 25, vesicle associated membrane protein and syntaxin) in the nerve endings, which in turn inhibits the binding of acetylcholine vesicles with the cell membrane, thus inhibiting exocytosis. The $\mathrm{H}$ chain binds irreversibly to the surface of the presynaptic nerve ending causing permanent blockage to those existing receptors $[3,4]$. Onset of action usually requires $24-72 \mathrm{~h}$ to occur, peaking at about 10 days and fading of the toxin's action usually needs two to three months [5].
In 1973, Dr. Alan Scott introduced botulinum toxin to the medical field where he noted the effect of oral ingestion of the toxin both intraocular and extraocular muscles in the form of pupillary dilation, impairment of accommodation, ptosis and diplopia. He performed his experiment using Botulinum toxin A in thirteen eyes of eight rhesus monkeys, the effect was noted on the injected horizontal muscles producing permanent change in the ocular alignment [6].

That effect is believed to be due to transient weakness of the injected muscles and the permanent effect due to contracture of the antagonist muscle [6]. It is also believed that ocular alignment through botox enhances the sensory proprioception which in turn facilitates the endurance of that alignment $[7,8]$.

Scott injected his first human eye in 1977, and reported his results in 1980. Since that time, the uses of botulinum toxin in ophthalmology has substantially expanded. Indications included hemifacial spasm, essential blepharospasm, lid malposition, chronic dry eye and others $[9,10]$.

To our knowledge, all studies done in the region were limited to a specific strabismus entity or tackling a specific botox intervention. Our aim of this study is to analyze the indications, effectiveness and side effects of Botulinum toxin in the 
management of different horizontal strabismus entities in Saudi Arabia, represented by a tertiary hospital.

\section{Methods}

Design: Retrospective cohort study.

After acquiring approval of the research committee in Dhahran Eye Hospital (DESH), Dhahran, Saudi Arabia, all 110 patients underwent botox injection for strabismus from November 2013 till September 2016 were considered for analysis. The exclusion criteria were (1) Previous botox injections outside DESH, (2) Previous strabismus surgery (3) Previous orbital decompression surgery, (4) Facial trauma with orbital bone fractures, (5) Previous scleral buckle surgery.

File review included the following:

i. Detailed perinatal history, detailed history of strabismus, previous treatment.

ii. Complete ophthalmologic and orthoptic assessment: visual acuity (LogMar), extraocular muscle movements, angle of deviation for distance and near, slit lamp examination, dilated fundus exam, cycloplegic refraction and spectacle correction.

iii. Final diagnosis, options offered for treatment.

iv. Procedure: After proper pre-op assessment, each patient was taken to the operating room, inhalational anesthesia was administered, the injection site was chosen according to the usual anatomical site of the intended muscle (according to spiral of tillaux) [11]. Dose of botox was variable according to surgeon's preference and own experience ( 2.5-10 IU).

v. Post injection follow-up: All patients were seen for at least 3 times post injection. First visit ranged from two to three weeks, second visit from six to eight weeks and third visit from four to five months. On the first visit the deviation of the eye was documented as esotropia, exotropia or orthophoria. The presence or absence of ptosis was also documented subjectively. On the consecutive visits the exact angle of deviation was measured by the surgeon and by an independent orthoptist, documentation of lid position, compliance on treatment of amblyopia (defined as "decrease of visual acuity for which no causes can be detected by the physical examination of the eye, caused by vision deprivation or abnormal binocular interaction") [12] if any.

The main indicator of success in the study is the residual angle of horizontal strabismus which allows for the development of binocularity, i.e. a residual angle of 10 prism diopters (PD) or less is generally acceptable [13-15].

Vertical deviation or the need for surgical intervention for inferior oblique over-action (IOOA) was not considered as a failure. Yet, proceeding to a surgical intervention for horizontal deviation or a remaining angle more than 10 PD after the third post injection visit were considered as failure indicators, unless reinjection was decided.

All categorical data were represented by frequency with percentage and it was analyzed by using Chi-square and Fisher exact test. Continuous data were presented by mean with standard deviation and it was analyzed by using independent ttest. All the analysis was done by using SPSS 21.0 version. A p value less than 0.05 were considered significant.

\section{Results}

Out of the 110 cases, 36 cases were excluded either due to the previous exclusion criteria or due to insufficient data. The final sample was 74 , with $52.7 \%$ males $(n=39)$ and $47.3 \%$ females $(n=35)$ (Figure 1). Age of participants ranged from two months to forty-five years, with the majority of cases (54\%) lying within one to five years (Figure 2). The most prevalent diagnosis was partially accommodative esotropia, followed by infantile esotropia (Table 1).
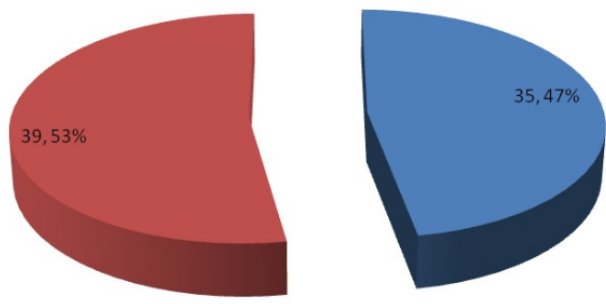

- Female male

Figure 1. Males $(n=39)$ and $47.3 \%$ Females $(n=35)$.

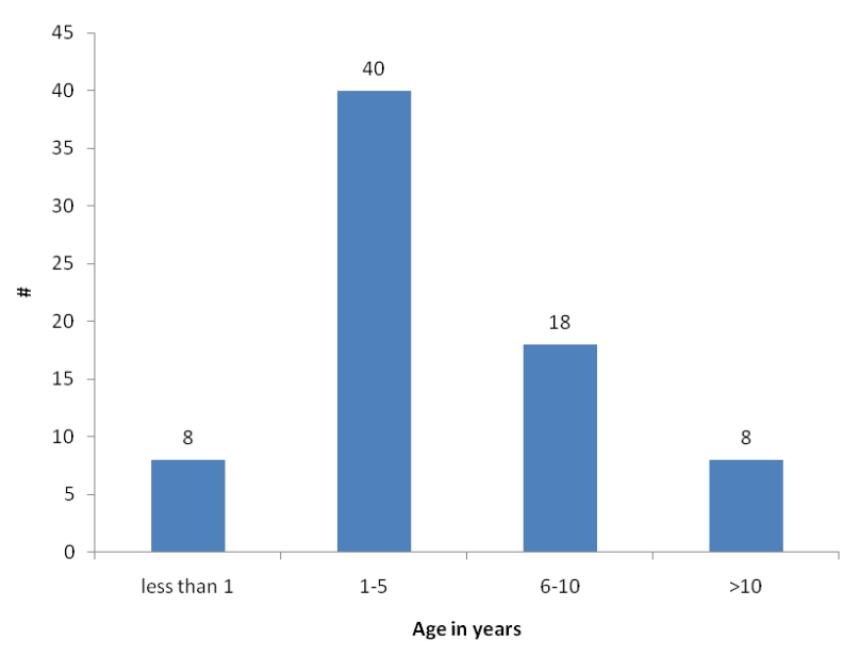

Figure 2. Majority of cases lying within one to five years.

Table 1. Diagnosis of patients.

\begin{tabular}{|c|c|c|}
\hline Diagnosis & Number & Percentage \\
\hline $\mathrm{PAET}^{*}$ & 34 & 45.9 \\
\hline Infantile Esotropia & 22 & 29.7 \\
\hline Sensory ET** & 6 & 8.1 \\
\hline Non-Accommodative ET & 3 & 4.1 \\
\hline
\end{tabular}


Citation: AA Taisan, FT Shamlan, AK Mulhim, et al.. Botulinum toxin; indications, success rates and complications in the management of horizontal strabismus in Saudi Arabia. J Clin Ophthalmol. 2018;2(1):32-37.

\begin{tabular}{lll}
\hline Duane type I & 3 & 4.1 \\
\hline Sensory $\mathrm{XT}^{\star * *}$ & 2 & 2.7 \\
\hline Acquired Esotropia & 1 & 1.4 \\
\hline Intermittent XT & 1 & 1.4 \\
\hline
\end{tabular}

${ }^{*}$ Partially accommodative esotropia.

\section{** Esotropia}

*** Exotropia

Visual acuity was objectively measured in $62 \%$ of patients $(n=46)$. The mean in the right eye was $0.27 \pm 0.341$ while in the left eye was $0.28 \pm 0.339$ (Figures 3 and 4).
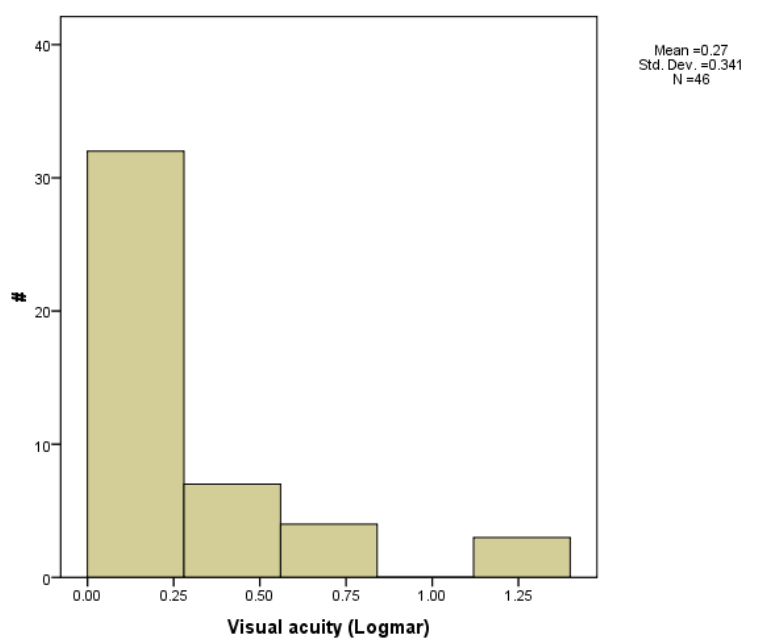

Figure 3. The mean in the right eye was $0.27 \pm 0.341$.

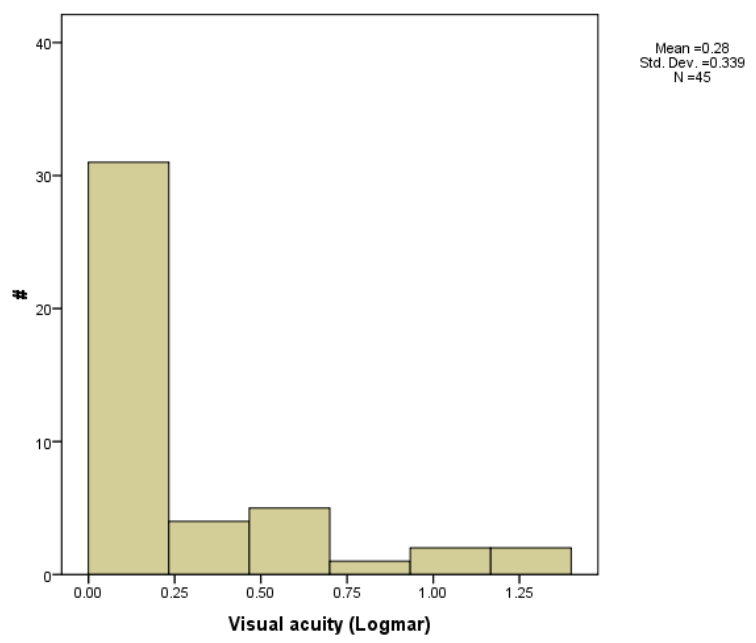

Figure 4. The mean in the left eye was $0.28 \pm 0.339$.

Extraocular movement assessment was reviewed, 39 (52.7\%) patients were having full extraocular movement with no overacting muscles while the most prevalent extraocular muscle abnormality was inferior oblique overaction (33.7\%).

The mean angle of deviation for near was $37.3 \mathrm{PD}$ with a range of 10 to $90 \mathrm{PD}$, whereas for distance (at 20 feet) was $30 \mathrm{PD}$ and a range of 10 to $65 \mathrm{PD}$ (Figure 5).

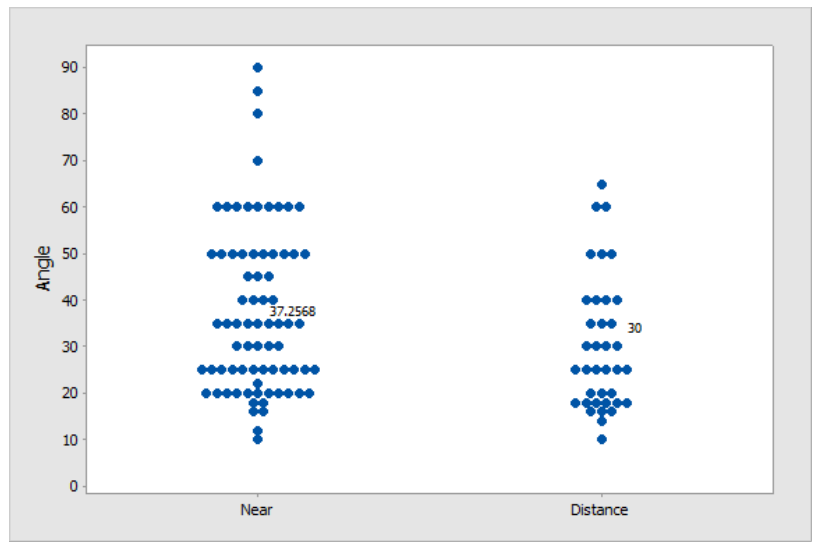

Figure 5. Mean angle of deviation.

Out of the 74 participants $78.4 \%(n=58)$ received injection only once whereas $21.6 \%(\mathrm{n}=16)$ of the patients received injection twice. The average dose of first injection was 7.3 international units (IU) and the second injection was 5 IU (Figure 6).

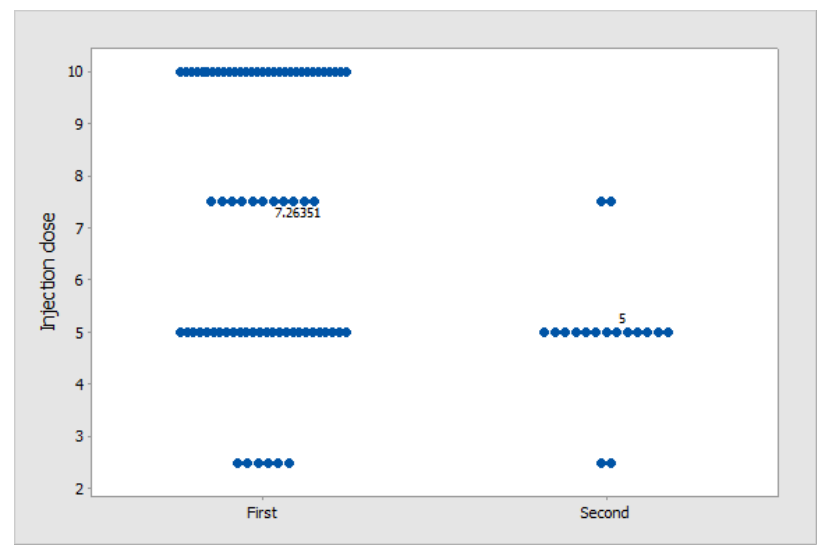

Figure 6. The average dose of first injection was 7.3 international units (IU) and the second injection was $5 I U$.

The overall success rate was $54.4 \%(n=40)$ after a minimum follow up period of four months post injection (ranging from four months to three years). The age, angle of deviation and amblyopia were not statistically significant. However, when analyzing each clinical entity separately, we found that the success rate in PAET was $70.6 \%(\mathrm{n}=24)$ (Table 2).

Table 2. Success vs. diagnosis.

\begin{tabular}{ll}
\hline Diagnosis & Success $(\%)$ \\
\hline PAET $(n=34)$ & $24(70.6 \%)$ \\
\hline Infantile ET $(n=22)$ & $8(36.4 \%)$ \\
\hline Sensory ET $(n=6)$ & $1(16.7 \%)$ \\
\hline Non-accommodative ET $(n=3)$ & $2(66.7 \%)$ \\
\hline Duane type I $(n=3)$ & $2(66.7 \%)$ \\
\hline Sensory XT $(n=2)$ & $1(50 \%)$ \\
\hline Acquired ET $(n=1)$ & $1(100 \%)$ \\
\hline
\end{tabular}


Intermittent XT $(\mathrm{n}=1)$

$0(0 \%)$

The success rate was analyzed in regards to age, angle of deviation, and the presence of amblyopia. None of which was clinically significant (Tables 3-5).

Table 3. Success vs age.

\begin{tabular}{lllll}
\hline Success & N & Mean age & Std. Deviation & P value \\
\hline Yes & 40 & 5.68 & 7.04 & 0.52 \\
\hline No & 34 & 6.88 & 9.04 & \\
\hline
\end{tabular}

Table 4. Success vs. amblyopia.

\begin{tabular}{|c|c|c|c|c|}
\hline & & \multicolumn{2}{|c|}{ Success } & \multirow[t]{2}{*}{$P$ value } \\
\hline & & Yes & No & \\
\hline \multirow[t]{4}{*}{ Amblyopia } & Yes & 15 & 14 & 0.72 \\
\hline & & $51.70 \%$ & $48.30 \%$ & \\
\hline & No & 25 & 18 & \\
\hline & & $(58.1 \%)$ & $(41.9 \%)$ & \\
\hline
\end{tabular}

Table 5. Success vs angle of deviation.

\begin{tabular}{llllll}
\hline & Success & No. & Mean & $\begin{array}{l}\text { Std. } \\
\text { Deviation }\end{array}$ & P value \\
\cline { 1 - 4 } Angle: near & Yes & 40 & 33.73 & 15.83 & 0.06 \\
\cline { 2 - 5 } & No & 34 & 41.41 & 19.25 & \\
\hline $\begin{array}{l}\text { Angle: } \\
\text { distance }\end{array}$ & Yes & 23 & 28.43 & 12.93 & \multirow{2}{*}{0.4} \\
\cline { 2 - 5 } & No & 14 & 32.57 & 16.25 & \\
\hline
\end{tabular}

Upon further analysis of PAET; the entity with the highest number of cases and the highest success rate, there was no statistical significance of age, angle of deviation or presence of IOOA. However, the absence of IOOA had a significant impact on the success rate in infantile esotropia. Out of the three Duane cases, two showed success, and IOOA was not present in any of the three cases, thus the statistical significance doesn't apply in this situation. (Table 6).

Table 6. Success vs presence of IOOA.

\begin{tabular}{llll}
\hline Diagnosis & Success & Success & P value \\
\cline { 2 - 3 } & With 100A & Without 100A & \\
\hline PAET & 12 & 12 & 0.595 \\
\hline Infantile ET & 0 & 8 & 0.03 \\
\hline Sensory ET & 0 & 1 & NA \\
\hline Non-acc. ET & 1 & 1 & NA \\
\hline Duane type I & 0 & 2 & 0.04 \\
\hline Acquired ET & 0 & 1 & NA \\
\hline Sensory ET & 0 & 1 & NA \\
\hline
\end{tabular}

\begin{tabular}{llll}
\hline Intermittent XT & 0 & 0 & NA \\
\hline
\end{tabular}

Complications: There were no serious peri-operative complications documented (scleral perforation, retinal detachment, endophthalmitis). In the first post injection visit, ptosis was present in $39.2 \%$ and $5.4 \%$ in the first and second injections respectively, while in the second post injection visit it dropped dramatically $(2.7 \%$ and $1.4 \%$ respectively). One of the participants maintained ptosis up to the third follow up visit. However, the patient missed the follow up visits. On the other hand, consecutive exotropia (assessed in cases received botox injections for esotropia) was present in $57.7 \%$ and $9.8 \%$ in the first and second injections respectively, the rate dropped in the second post injection visit in both (first and second injection) to $9.8 \%$ and $2.8 \%$ respectively. One case was having sensory esotropia with visual acuity of 20/20 (logMAR zero) in the right eye and 20/100 (logMAR 0.70) in the left eye. The angle of deviation was 60 PD measured at near and distance. The patient presented in the first post injection visit with ptosis and exotropia, consecutive exotropia of $25 \mathrm{PD}$ and $20 \mathrm{PD}$ in the second and third post injection visit respectively. The final plan of the patient is yet to be determined.

The number of patients underwent different types of surgical interventions were 27 , which accounts for $36.48 \%$. The most frequent type of surgery was medial rectus recession; unilateral or bilateral $(\mathrm{n}=15)$ followed by simultaneous recession and resection of the horizontal rectus muscles.

\section{Discussion}

The study analyzed the success rate of botulinum toxin injection in strabismus cases. In our series, the most prevalent diagnosis was esotropia with a rate of $89 \%$ which is considered higher than the expected rate of esotropia among strabismus cases in general. That can be attributed to the surgeons' preferences where most exotropia cases were elected to be managed surgically. No large-scale studies were found to compare our prevalence with.

In our study, the injection dose ranged from 2.5 to 10 IU per muscle and was according to the surgeons' preference and experience. Furthermore, no clear guideline for the doses of botulinum toxin in strabismus was found neither according to the angle of deviation, nor the type of strabismus in the literature when using PubMed and Google Scholar search engines. However, the doses in our study were consistent with the doses used generally in other studies. For example, Merina PS. et al. used a dose ranged from 2.5 to 22.5 IU per muscle [16].

Due to the low number of exotropia cases, comparing Esotropia versus exotropia was not possible. The overall success rate was 54\% with PAET being highest $(70.6 \%)$. Lower rate of success was found in infantile ET (36.4\%). Furthermore, the presence of IOOA had significant effect on the success rate in cases of infantile ET in contrast to cases of PAET where the eight successful cases of infantile ET were not having IOOA, on the contrary, none of the cases with IOOA succeeded. No clinical significance was found regarding age, 
Citation: AA Taisan, FT Shamlan, AK Mulhim, et al.. Botulinum toxin; indications, success rates and complications in the management of horizontal strabismus in Saudi Arabia. J Clin Ophthalmol. 2018;2(1):32-37.

angle of deviation or amblyopia. Our results are consistent with Leffler CT et al. that studied the rates of reoperation and abnormal binocularity following strabismus surgery and botox injection. They found that botulinum toxin injection in children under 2 years is associated with higher reoperation rate due to the improper alignment of the eyes in the early post injection period leading to loss of fusion and subsequent failure [17]. This could explain the higher rate of success in PAET cases in our study compared to those with infantile ET, since accommodation and fusion are important components in PAET. Thus, caution is recommended when deciding to give botox injection in the early visual developmental age although there are studies suggesting using botox as early as possible [18].

Although horizontal muscle recession is still considered a preferable intervention in Duane syndrome [19], Talebnejad et al. treated three patients with Duane syndrome type 1 and one patient with type 2 with botox. [20] In all cases the angle of deviation and the severity of leash phenomenon was reduced. Since then, several reports have shown the effect of botulinum toxin in either producing orthophoria or reducing the angle and thus reducing the amount of muscle recession [21-23]. In our study, 3 cases of Duane syndrome type I were included with a success rate of $66 \%$.

There were no serious complications in the early or late post injection period. Ptosis and exotropia in the first post-injection visit were considered as desired outcomes since their presence implies the positive effect of the injection, and they almost resolved in the second post injection visits. Furthermore, no complications were documented regarding anesthesia, which might be attributed to the use of mask anesthesia instead of the more traumatizing endotracheal intubation used with general anesthesia performed in all cases of pediatric strabismus surgeries. Furthermore, it helps avoiding the decrease in cognitive functions related to general anesthesia in early childhood [24].

One of the withdraws of this study was the absence standardization of visual acuity documentation. Furthermore, objective visual acuity assessment was not possible for all patients, and due to that, presence or absence of amblyopia was used instead of visual acuity in our comparison.

Incomplete documentation of near and distant angles for all patients prior to botox injection was another withdraw. Moreover, only near angle of deviation was documented in the first post injection visit. As a result, the interpretation of the clinical significance for near and distant angles had to be done separately.

\section{Conclusion}

Botulinum toxin represents a safe, repeatable alternative to surgery in the management of different entities of strabismus. Success rate differs in different diagnoses with PAET scoring the highest. Presence of inferior oblique overaction leads to a significant lower rate of success in infantile ET. In our study, we couldn't find definitive factors affecting the success rate. Further large scale, prospective studies are needed to explore the effectiveness of botulinum toxin in certain strabismus entities.

\section{References}

1. Münchau A, Bhatia KP. Uses of botulinum toxin injection in medicine today. BMJ. 2000;320:161-5.

2. Ellenhorn MJ, Barceloux DG. Diagnosis and treatment of human poisoning. New York: Elsevier; Med Toxicol. 1988;1185-7.

3. Sellin LC. The pharmacological mechanism of botulism. Trends Pharmacol Sci. 1985;6:80-2.

4. Stanley EF, Drachman DB. Botulinum toxin blocks quantal but not non-quantal release of $\mathrm{ACh}$ at the neuromuscular junction. Brain Res. 1983;261:172-5.

5. $\mathrm{P} \mathrm{K}$ Nigam, Anjana Nigam. Botulinum toxin. Indian $\mathrm{J}$ Dermatol. 2010;55: 8-14.

6. Scott AB, Rosenbaum A, Collins C. Pharmacologic weakening of extraocular muscles. Invest Ophthalmol. 1973;12:924-7.

7. Sánchez AV, Ferreiro, Miguéns Vázquez X. Strabismus and botulinum toxin. Arch Soc Esp Oftalmol. 2013;88:286-7.

8. Simonsz HJ, Kolling GH, Unnebrink K. Final report of the early vs. late infantile strabismus surgery study (ELISSS), a controlled, prospective, multicenter study. Strabismus. 2005;13:169-99.

9. Dutton J, Fowler A. Botulinum toxin in ophthalmology. Surv Ophthalmol. 2007; 52:13-31.

10. Emel Başar, Ceyhun Arıcı. Use of botulinum neurotoxin in ophthalmology. Turk J Ophthalmol. 2016;46:282-290.

11. Remington LA. Clinical anatomy and physiology of the visual system, 3rd ed. New York: Elsevier; 2012:187.

12. Von Noorden GK. Binocular vision and ocular motility. St Lous: Mosby; 1996.

13. Leska DA, Holmes JM. Maximum angle of horizontal strabismus consistent with true stereopsis. J AAPOS. 2004;8:28-34.

14. Khan AO. Two horizontal rectus eye muscle surgery combined with botulinum toxin for the treatment of very large angle esotropia. A pilot study. Binocul Vis Strabismus Q. 2005;20:15-20.

15. Ganguly S, Pradhan R. Effect of monocular surgery for large-angle horizontal deviation in adults. Nepal $\mathrm{J}$ Ophthalmol. 2011;3:27-30.

16. Merino PS, Vera RE, Mariñas LG, et al. Botulinum toxin for treatment of restrictive strabismus. 2017;10:189 93.

17. Leffler CT, Vaziri K, Schwartz SG, et al. Rates of reoperation and abnormal binocularity following strabismus surgery in children. Am J Ophthalmol. 2016;162:159-66.

18. Campos EC. Why do the eyes cross? A review and discussion of the nature and origin of essential infantile esotropia, microstrabismus, accommodative esotropia, and acute comitant esotropia. J AAPOS. 2008;12:326-31 
19. Farvardin M, Rad AH, Ashrafzadeh A. Results of bilateral medial rectus muscle recession in unilateral esotropic Duane syndrome. J AAPOS. 2009;13:339-42.

20. Talebnejad MR, Sahraian N, Eghtedari M. Management of Duane's syndrome with botulinum toxin injection. Iranian J Ophthalmol. 2008;20:10-14.

21. Dawson EL, Maino A, Lee JP. Diagnostic use of botulinum toxin in patients with Duane syndrome. Strabismus. 2010;18:21-23.

22. Maya JF, De Liaño RG, Catalán MR, et al. Botulinum toxin treatment in patients up to 3 years of age who have esotropic Duane retraction syndrome. Strabismus. 2013;21:4-7.

23. Ameri A, Farzbod F, Bazvand F, et al. Botulinum toxin injection in the patients with Duane syndrome type 1. J Curr Ophthalmol. 2017;29:50-53.
24. Backeljauw B, Holland SK, Altaye M, et al. Cognition and brain structure following early childhood surgery with anesthesia. Pediatrics. 2015;136: e1-12.

\section{*Correspondence to}

Abdulaziz A Al Taisan

2430 Prince Majed St. Hofuf, Saudi Arabia

Tel: +966500188442

E-mail: dr.altaisan@gmail.com 